\title{
Development of Activity Based Lesson Plans: An Experiment with Social Science Subject
}

\author{
Baljeet Singh \\ Research Scholar, Faculty of Education, Mewar University, Chittorgarh (Raj) \\ Dr. Shruti Kant Pandey \\ Amity University Uttar Pradesh, Noida (UP)
}

\begin{abstract}
Teacher effectiveness is a broadly used term that consists of characteristics, proficiencies, teaching skills and behaviours of teachers at all educational levels that empower students to reach to desired level. This may include the accomplishment of precise learning objectives as well as broader learning goals such as being able to solve problems, think critically, work collaboratively, and become effective citizens. In the present investigation, Review of related literature revealed that there is a gap in expected and existing competencies of social science teachers. One of the major findings of these studies revealed that teachers in our own country are mostly following fixed ways of teaching in the classroom. It is because the education program for teachers prepares the teacher to follow one of a few fixed ways of teaching. Therefore, a strong need of development of activity-based lesson plans teachers which will update their knowledge and skills for effective social science teaching. Therefore this paper deals with the development of Activity Based lesson plans for effective teaching in social sciences (ABTM)
\end{abstract}

Keywords: Activity Based Lesson Plans, Teaching modules in social science

DOI: $10.7176 /$ RHSS/9-7-04

Publication date: April $30^{\text {th }} 2019$

\section{Introduction}

Education is the basic necessity for the human being for the survival in a society. The foundation of our society apprehends education not only as education accessible to all but also as education whose aims and methods have been continuously and consistently thought out afresh along the passage of time. National development is wideranging in scope and it is essentially the result of human efforts. In modern age, education is generally known for the profitable experience. Further these experiences help individuals in gaining knowledge for the selfdevelopment. When we talk of giving education to our youth, we mean providing such experiences which may help them grow individually- physically, mentally, morally and spiritually. It is well proved that every society has great expectations from its teachers. Therefore, time to time, government makes various provisions for the training of the teachers and their professional development. Since independence many policies have been introduced to improve the education system. Education Commission (1964-66) makes it cogent thus, "Of all the different factors that influence the quality of education and its contribution to national development, the quality, competence and character of teachers are undoubtedly the most significant."

Investment in education to a country is a sign to improve the quality of its population. This signifies that knowledge received through educations determines to a great extent the future of mankind. We know that inadequate education is associated with poverty, unemployment and deviant behaviour. As long as the quality of education is not improved, students as well as teachers won't be able contribute much in the present society. The key point is to improve an educational system is to reform teacher education (Hallinan and Khmelkov, 2001). According to Walter, Wilkinson and Yarrow (1996) "the quality of teaching depends on the quality of the teachers which, in turn, depends to some extent on the quality of their professional development". Without well trained, qualified and committed teachers it is impossible to deliver effectively functioning educational systems (Unwin, 2005). In fact, to meet the challenges of globalization, teachers are required to gain the necessary skills and knowledge. As Smaldino, Lowther and Russell (2008) state, the teacher in tomorrow's classrooms needs to exemplify a willingness to explore and discover new technological capabilities that enhance and expand learning experiences. In this aspect, professional development programs for teachers have always been essentially important. Those programs enable teachers to become highly qualified by improving, increasing and advancing their knowledge through a better understanding of effective instructional strategies. On the other hand, to improve teacher quality, teacher development needs should be identified first. Based on teachers' professional needs, information and communication technology (ICT) can take on important roles in support of those professional development programs. According to Moyle (2007), professional development of teachers is conducted on the assumption that improved teacher capabilities, e.g. in integrating educational technologies into their teaching, will in turn improve student learning outcomes. In this paper, a theoretical approach is used to define a framework for effective and successful implementation and integration of information and 
communication technologies and need analysis in teacher training programs. The aim is to highlight a set of parameters that are essential for a successful professional development program for teachers. Therefore by and large performance of teachers depends on the quality of training they received. Similarly it is also fair to mention that quality of content provided to learners enhances the achievement of the students (Pandey and Ameta, 2017).

\section{NEED IDENTIFICATIONS}

Investment in population quality and in knowledge determines to a great degree the future of its citizens. It is already known that inadequate education is associated with poverty, unemployment and deviant behavior (Schultz,1981). Traditionally it is believed that every teacher teaches in the way he was taught by his favorite teacher. Therefore, the traditional methods of teaching kept perpetuating without evaluation for a quite long time. But the emergence of modern technology, psychology and philosophy in the field of education has brought tremendous changes in the teaching and learning methodologies. There have come several formal techniques, approaches and models which are gaining popularity now a day due to their usability and effectiveness. Even then, most of teachers especially in social sciences use old-fashioned techniques of transferring the knowledge and understanding involved in these courses. This often results into lessoning of interest and lack of predestined outcomes. Resulting, the whole process of taking up the social sciences at school level comes under a big question. To avoid such uninvited situations, it is necessary to devise and use state of art mechanisms and teaching-learning technologies in the realm of teaching of social sciences. Researchers therefore felt a strong need for development of an activity-oriented need based training module for developing effective social science teachers.

\section{DEVELOPMENT OF TRAINING MODULES FOR EFFECTIVE SOCIAL SCIENCE TEACHING}

On the basis of the review of related literature and identification of the need of social science it can be concluded that there exist an urgent need of developing a training module for effective social science teaching. The present study deals with the steps of designing the model plans for social science teaching.

The objective of the present study is to develop model lesson plans in the area of social science based on identified determinants of teaching effectiveness and perceived training needs of elementary school teachers.

The model of the lesson plans is need based. This can be represented as follows:

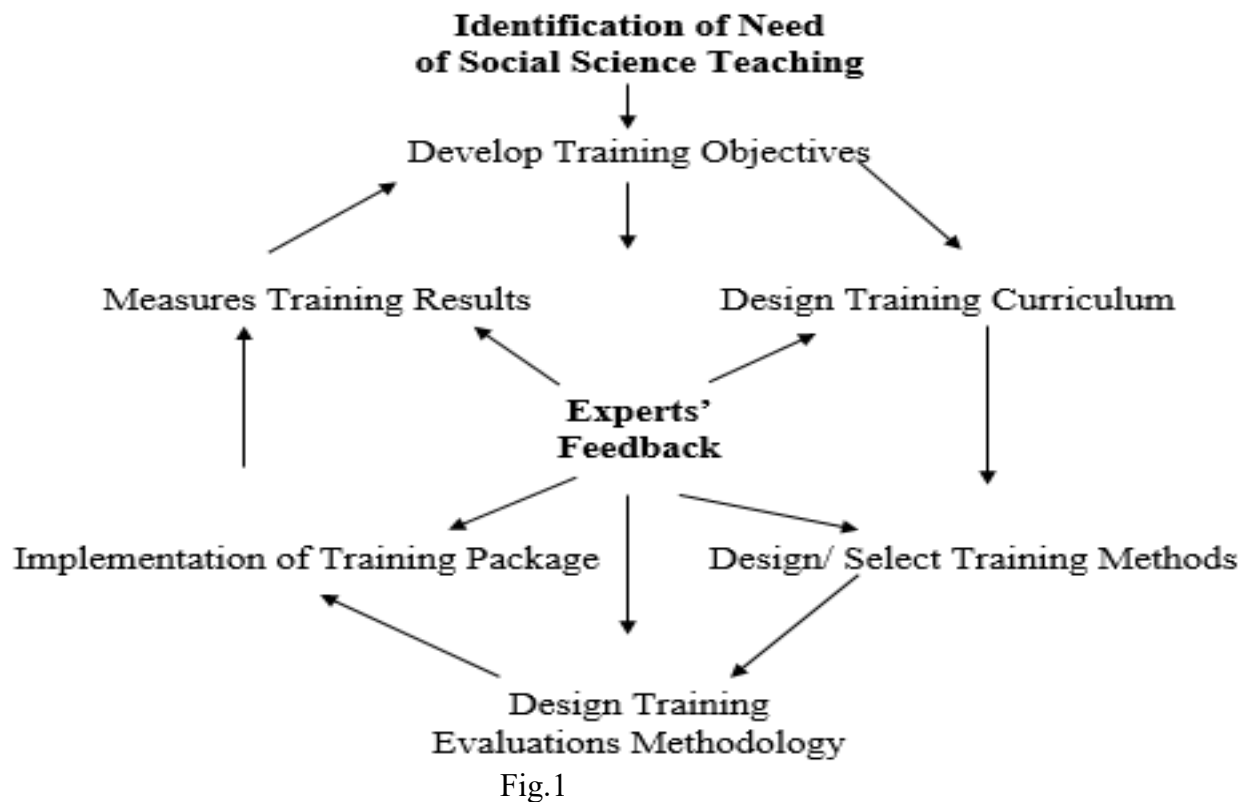

This model for developing the training modules has its root in the identification of need of social science teaching at elementary level. These are context and content specific and based on the topics covered in the prescribed syllabus at elementary level. Each topic has its specific pedagogical requirements. For example, if a teacher has to teach a topic 'Diversity and Discrimination', he or she has to plan it in a way that it can be linked with the real-life examples so that it could explain the conceptual clarity about the concept of Diversity as well Discrimination. At the same time, it should learner- centered and preferably activity based so that children can develop a better understanding and comprehension. 


\section{DIVERSITY AND DISCRIMINATION: A MODEL LESSON PLAN FOR ELEMENTARY LEVEL}

Based on the expert feedback and rigorous review of the literature following steps were followed to develop activity-based lesson plans.

1. The introductory part of the plan should have previous knowledge and activity based therefore for this topic we can start with the activity of labelling a picture of Dr. Bhimrao Ambedkar.

2. The lesson can be evolved with the help of asking the students to explore about Dr. Ambedkar and write few lines about him.

3. Examples from daily life can be used to explain the concept of discrimination. Students must be observing different cases of discrimination around them. A teacher should give different examples of diversity and discrimination to the students and ask them to identify them. For example, following task may be assigned to the students-

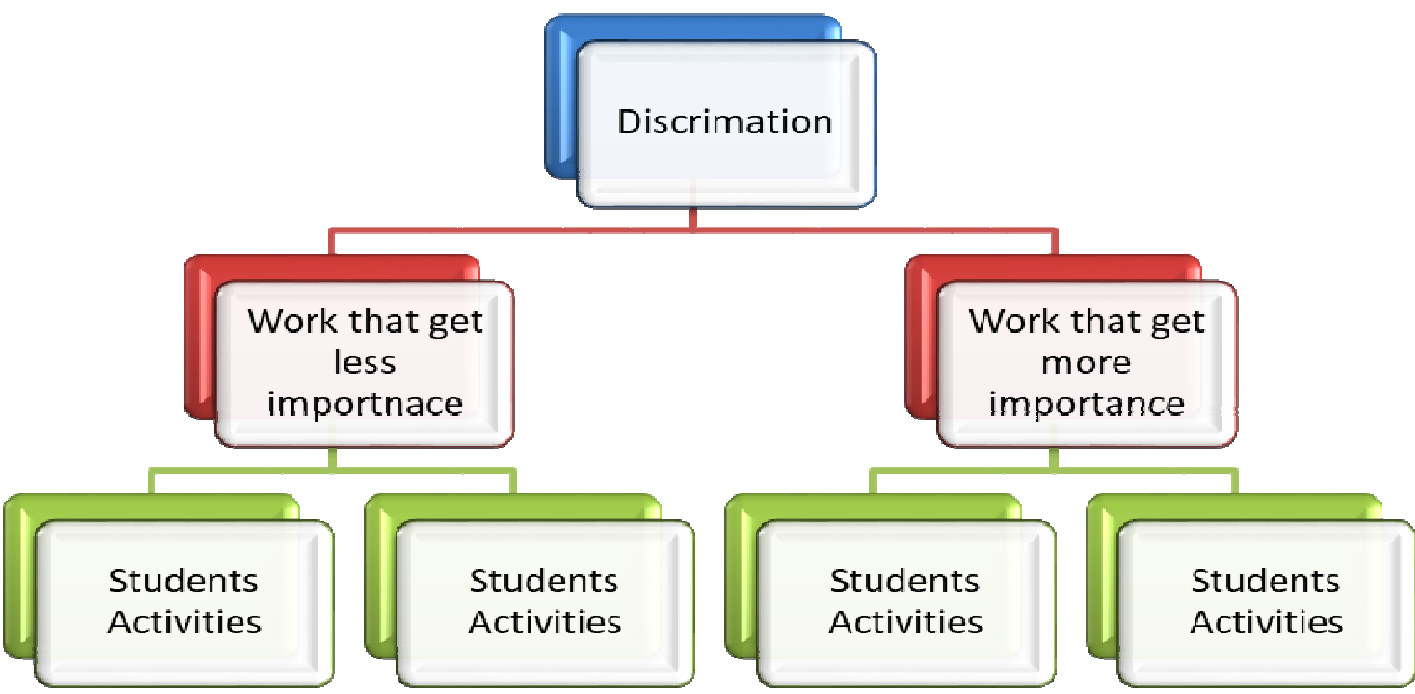

4. As a part of developing the lesson and to enhance the clarity of concept, a teacher may ask the students to write different examples of discrimination around them.

5. For better attainment of the concept of discrimination question based on the pictures will be useful. For example, a figure of Boy and Girl can be shown to the students and ask them to write some sentences on gender discrimination based on orthodox thinking in society.

6. Now the concept of discrimination can be again correlated with the life events of Dr. Ambedkar so that students can correlate and develop a better understanding of the concepts.

7. Information related to constitutional safeguard from discrimination can be explained through the contribution of Dr. Ambedkar. The students may be asked question related to different rights of constitution.

8. Learning may be evaluated through fill in the blanks, labelling of diagrams, odd one out and giving them activities related to collage making for the concept of diversity and discrimination. Activity based evaluation should be integral part of the whole evaluation plan

An Exemplary Lesson Plan

\section{Teaching Module for social Science \\ Activity Based Lesson Plan-1 \\ INSIDE OUR EARTH}

OBJECTIVES: The students will be able to

\section{Class VI}

COGNITIVE:-

1. Enlist various layers of earth.

2. List the various characteristics of rocks.

AFFECTIVE:

The students will be to:-

1. Realize the use of different rocks in daily life.

2. Learn the formation of the earth crust.

PSYCHOMOTOR

The students will be able to:- 
1. Label various layers of earth in diagrammatic form.

2. Draw the rock cycles.

\section{FILL THE TABLE}

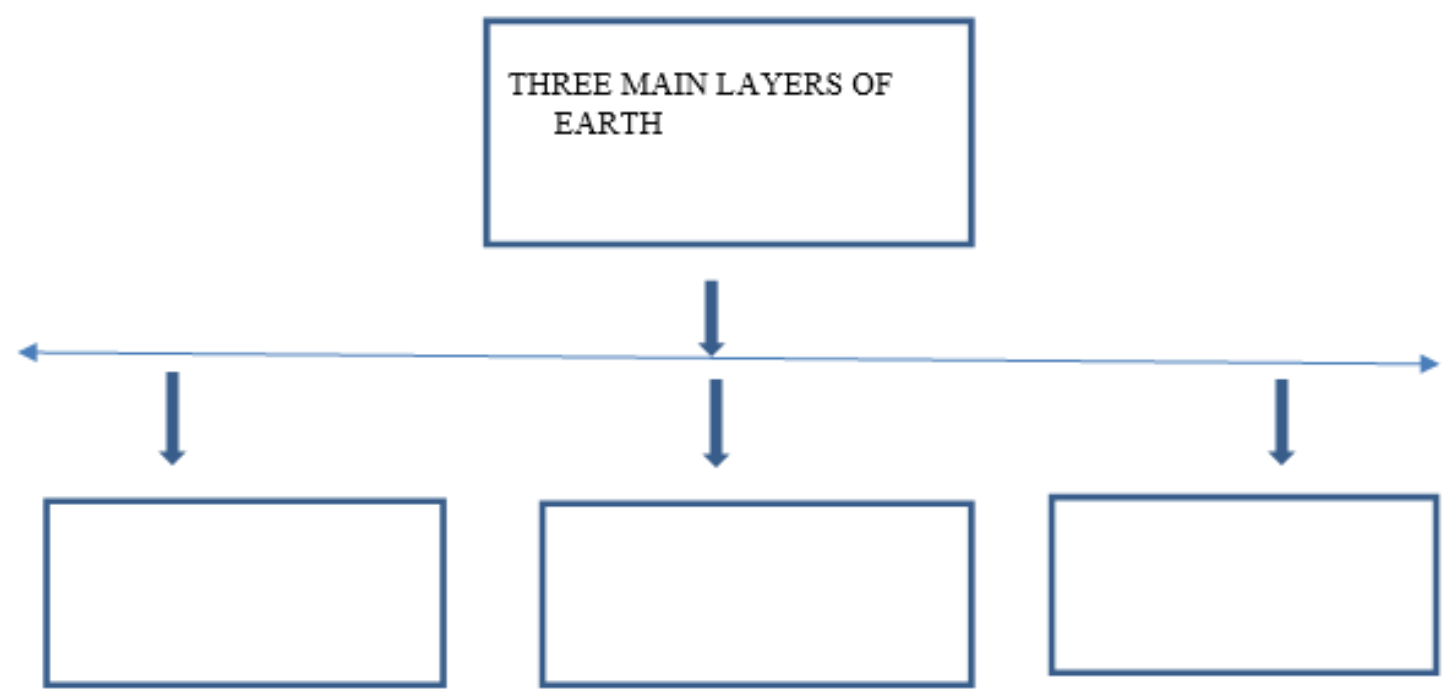

2.1 label them in the correct diagram: core, white, crust, mantle, shell, yolk.

2 Color the hottest part of the earth orange and color the mantle red

3. Color the surface of the earth blue and green to show oceans and Continents.
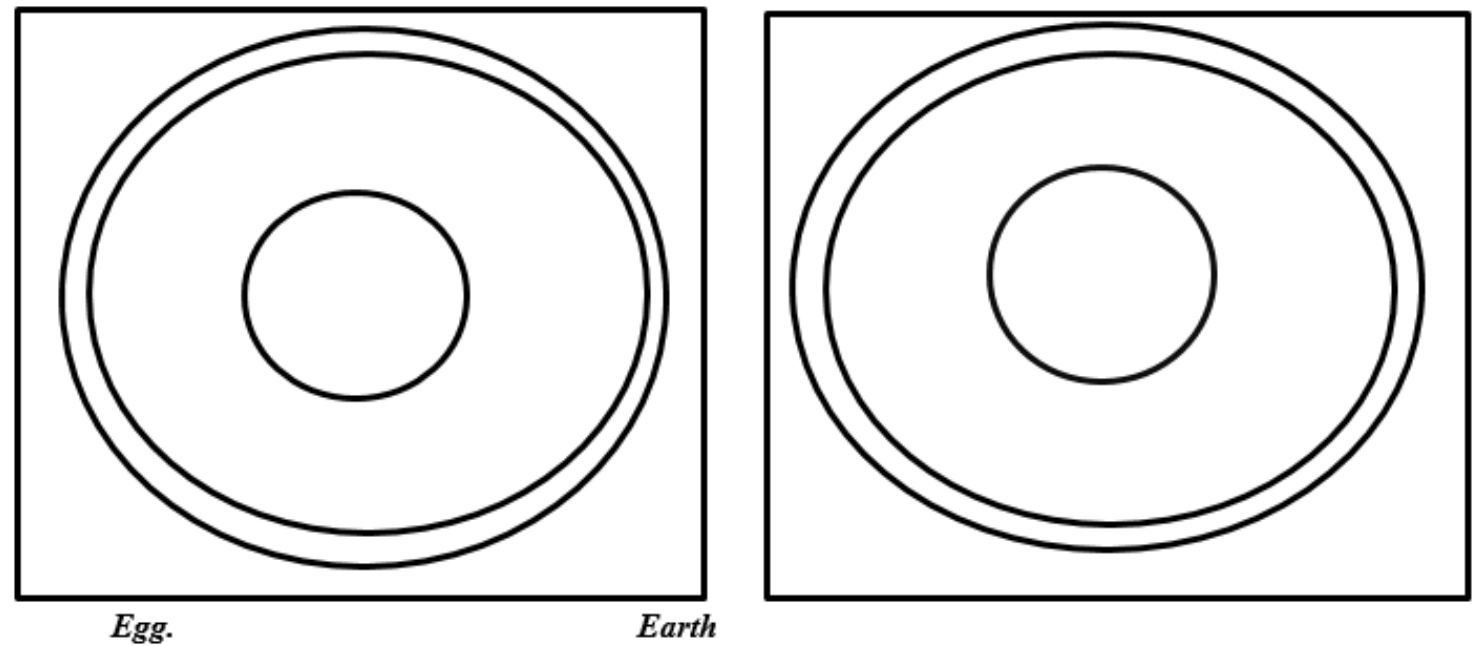

3. Write the uses of rocks and stones you see in your daily lives.

I) hard rock:

II) Stones:

4. Name the rocks used to build these Monuments 

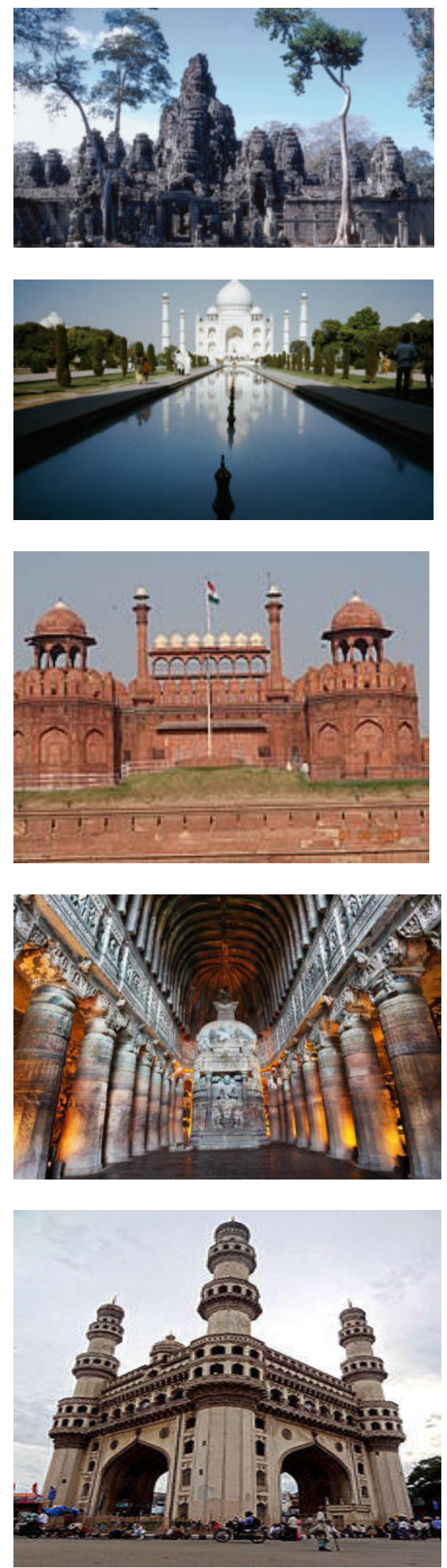


\section{Label the rock cycle}

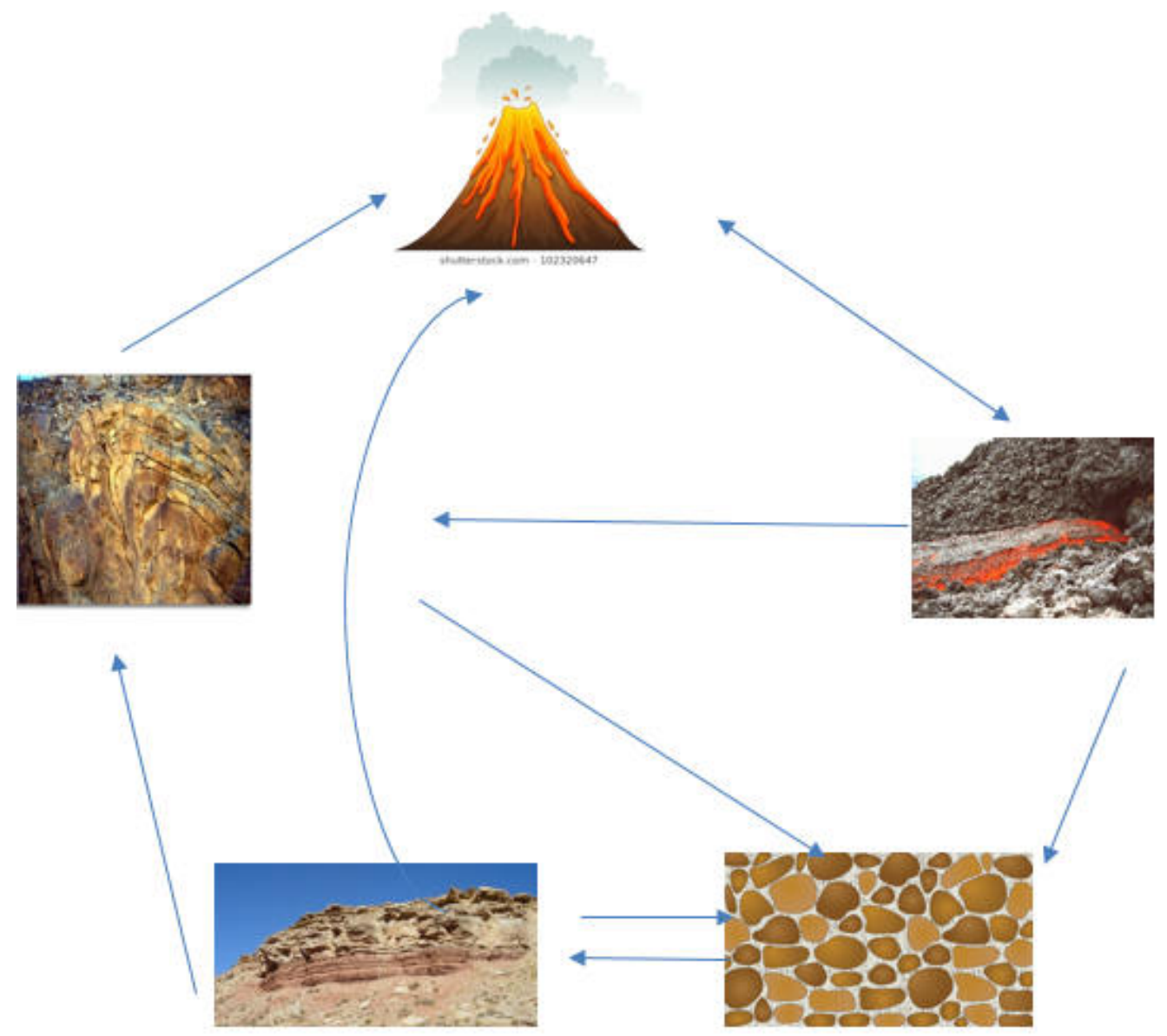

6. List Six objects and the mineral they are made of:-

\begin{tabular}{|c|c|}
\hline OBJECTS & MINERALS \\
\hline & \\
\hline & \\
\hline
\end{tabular}

7. Collect some samples or photos of minerals found in your surroundings and paste them in your notebooks. Above planning of a model lesson plan is an example of activity-based lesson plan that is integral part of the module. Every plan for the module may differ from each other based on the content and context and level of learners.

\section{ACTIVITY BASED LESSON PLAN -2 \\ HUMAN ENVIRONMENT - SETTLEMENT, TRANSPORT AND COMMUNICATION \\ CLASS VII}

OBJECTIVES: The students will be able to

Cognitive

- Define settlement

- Differentiate between Urban and Rural settlement.

- Recognise the importance of different modes of transport Affective

- Appreciate the use of transportation in their daily life

- Develop interest in the Human environment -settlement and transport Psychomotor

- $\quad$ Find different sea and air ports on map

- Collect pictures of different modes of transport 


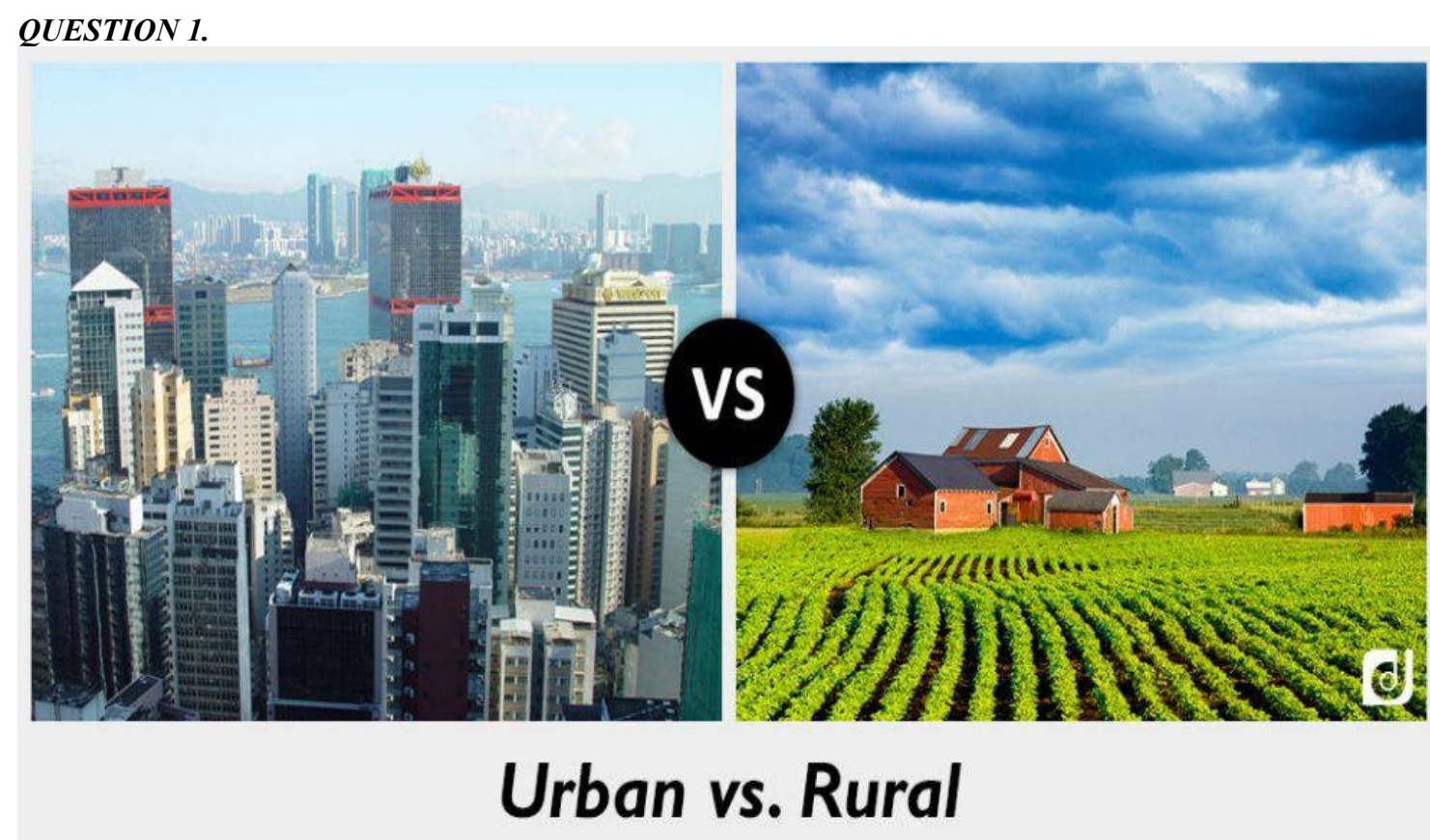

Write in detail about the two settlement referred in the picture above. Also write the difference between the Urban and Rural settlement.

\section{QUESTION 2.}

Collect and paste the pictures of activities performed by the people of Urban and Rural settlement in your scrap book.

QUESTION 3.

List the different modes of transport used by the students of your class while coming to school.

\begin{tabular}{|l|l|}
\hline 1. & 2. \\
\hline 3. & 4. \\
\hline 5. & 6. \\
\hline 7. & 8. \\
\hline
\end{tabular}

\section{QUESTION 4.}

A) Collect pictures and photographs of different modes of transport (i.e. roadways, railways, waterways and airways). Write 5-6 sentences under each picture.

\begin{tabular}{|l|l|l|l|}
\hline ROADWAYS & RAILWAYS & WATERWAYS & AIRWAYS
\end{tabular}

B) Make a list of different Major Sea Ports and Airports of a world.

\begin{tabular}{|c|c|}
\hline \multicolumn{1}{|c|}{ PORTS } & \multicolumn{1}{c|}{ AIRPORTS } \\
\hline Singapore and Mumbai in Asia. & Delhi and Mumbai airport \\
\hline & \\
\hline & \\
\hline & \\
\hline & \\
\hline & \\
\hline & \\
\hline C) Make list of Important National Highways of India. \\
\hline 2. & 5. \\
\hline 3. & 6. \\
\hline 4. & 7. \\
\hline
\end{tabular}




\section{QUESTION 5.}

A) Locate different SEA and AIR PORTS on the world map.

B) Locate different NATIONAL HIGHWAYS on the outline map of India.

\section{QUESTION 6.}

Human Environment-Settlement and transport

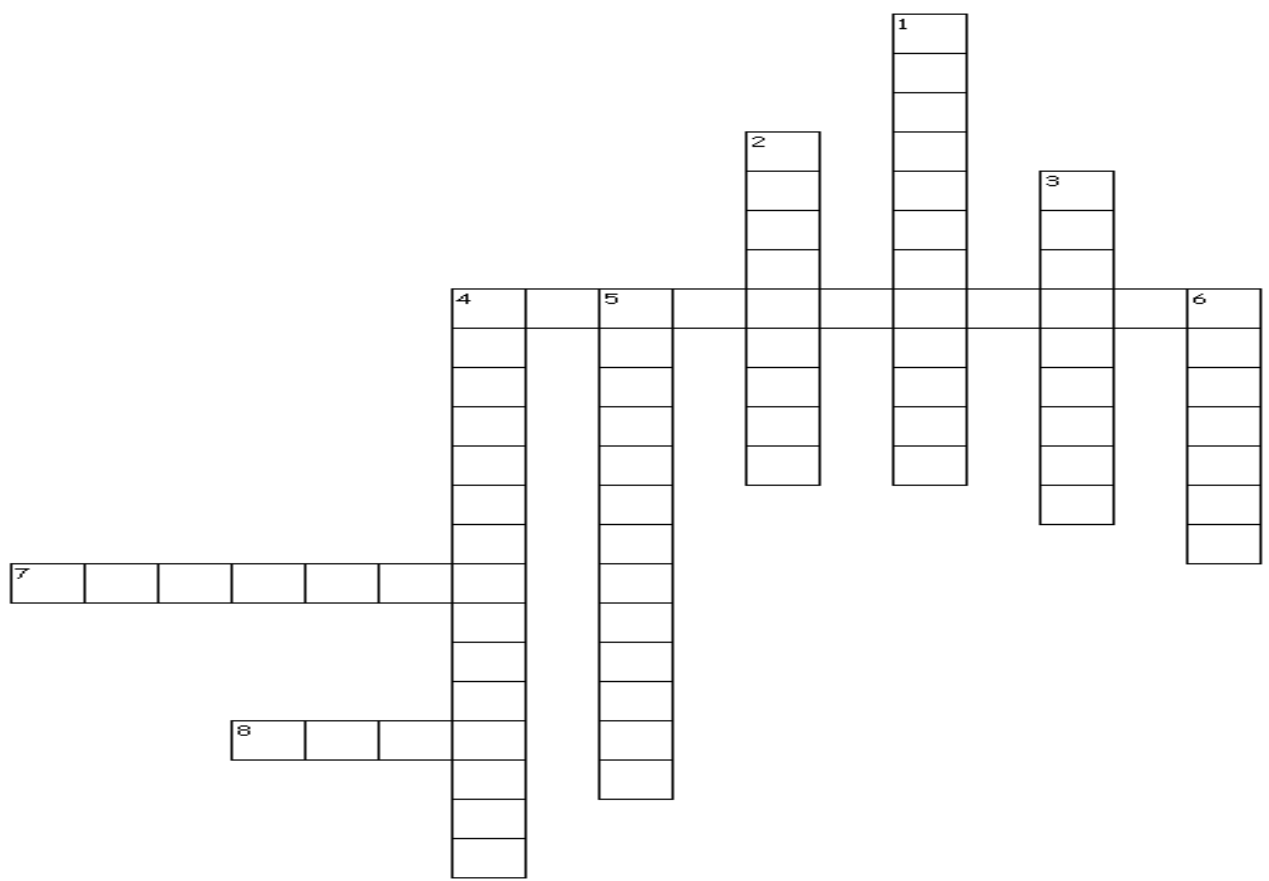

\section{Across}

4. are places where people build their homes.

7. it is the fastest means of transport developed in the early twentieth century.

8. is the largest Indian railway network.

\section{Down}

1. it is a seasonal movement of people.

2. highway in the Himalayan Mountains is one of the highest roadways in the world.

3 . is the means by which people and goods move.

4. have been introduced to make the journey faster.

5. is the longest railway system connecting St. Petersburg in Western Russia to Vladivostok on the Pacific coast.

6. roads built underground are called

\section{Conclusion}

Education does not set the boundaries of methods of teaching; it is entirely depend on the facilitators and learners that by which method of teaching and learning they find themselves comfortable. It is also depend on the situation and the environment and also learning experiences provided by the teachers to the learners. Therefore, selection of teaching methods should be need based. Present study has been carried out in need based direction. Henceforth, in the present study methods of the teachers have been emerged by analyzing the needs of elementary teachers. These innovative methods will play a pivotal role in enhancing the effectiveness of teaching -learning process in social science. Therefore, present lesson planning is an example of need based activityoriented lesson plan and it has been validated by the pedagogical experts. It carries a sound base for development of a teacher training module for effective teaching in social science at elementary level.

\section{References}

Hallinan, M.T., \& Khmelkov, V.T. (2001). Recent Development in Teacher Education in the United States of America. Journal of Education for Teaching, Vol. 27, No. 2.

Moyle, K. (2007). How can the value of educational technologies in schools be measured? Paper presented at the World Conference on Educational Multimedia, Hypermedia \& Telecommunications, Vancouver, Canada, 
June.

NCERT(2005) National Curriculum Framework. Delhi.

Pandey L. and Ameta D.(2017) Effect of Constructivist Based Training on Learning and Teaching: An Experiment in Classroom, Journal of Education and Practice, Vol 8, No 13.

Schultz, T.W. (1981). Investing in People: the economies of population quality. Berkeley: University of California Press.

Smaldino, Sharon E., Lowther, Deborah L., Russel, James D. (2008). Instructional Technology and Media for Learning. Pearson Merrill/ Prentice Hall.

Unwin, T. (2005). Towards a framework for the use of ICT in teacher training in Africa. Open Learning: The Journal of Open and Distance Learning, 20:2, 113-129.

Walter, J. M., Wilkinson, M. and Yarrow, A. (1996). Facilitating Professional development through the study of supervision and instructional change. British Journal of In-service Education, Vol. 22, No. 1, pp. 41-54. 